\title{
MULHERES INTEGRALISTAS: ENFERMEIRAS “BLUSAS-VERDES” A SERVIÇO DA NAÇÃO
}

\author{
Renata Duarte Simões, ${ }^{1}$ Ricardo Duarte Simões, ${ }^{2}$ Ticiana Ribeiro da Silva ${ }^{3}$
}

\footnotetext{
${ }^{1}$ Doutora em História da Educação e Historiografia. Pós-Doutoranda pelo Programa de Pós-Graduação da Faculdade de Educação da Universidade de São Paulo. Espírito Santo, Brasil. E-mail: renasimoes@hotmail.com

${ }^{2}$ Especialista em Terapia Intensiva e em Enfermagem Médico-Cirúrgica. Espírito Santo, Brasil. E-mail: ricsimoes@hotmail.com

${ }^{3}$ Especialista em Hemoterapia, Hematologia e em Enfermagem Neonatal. Espírito Santo, Brasil. E-mail: ticirj@hotmail.com
}

RESUMO: O estudo objetiva investigar a atuação designada à enfermeira integralista e a instrução que recebia para desempenhar com a máxima eficácia o seu papel nos quadros da Ação Integralista Brasileira, partido político de extrema direita, que emerge no Brasil, na década de 1930. Utiliza como fonte documental jornais integralistas, a coleção "Enciclopédia Integralista" e os prontuários sobre a Escola de Enfermagem Integralista que compõem o acervo criminal da Polícia Política, organizado pela Delegacia Especial de Segurança Política e Social. Como resultado, a pesquisa apresenta um expressivo investimento do integralismo na formação de enfermeiras, mulheres que aproveitaram o ensejo do momento para ampliar seus espaços sociais. Conclui que, embora o integralismo reforçasse os papéis descritos socialmente como femininos, a relação das mulheres com o movimento foi inovadora, pois possibilitou novas práticas e representações que elas passaram também a desenvolver na esfera pública, à exemplo, a atuação como enfermeiras.

DESCRITORES: História da enfermagem. Educação em enfermagem. Escolas de enfermagem.

\section{HOLISTIC WOMEN: “GREEN BLOUSE” NURSES TO THE SERVICE OF THE NATION}

\begin{abstract}
This study aims to investigate the role assigned to the holistic nurse and the education she receives to perform her role with maximum efficiency within the Brazilian Holistic Action (Ação Integralista Brasileira), a right-wing political party that emerged in Brazil in the 1930s. It uses holistic newspapers, the "Holistic Encyclopedia" collection, and records about the Holistic School of Nursing which compose the criminal collection by the Political Police, organized by the Special Police of Political and Social Safety as source material. As a result, the study presents a significant investment of holistic thinking in formally educating nurses, women who took the opportunity of the moment to expand their social arenas. It concludes that, although holistic thinking strengthened social roles described as female, the women's relationship with the movement was innovative because it enabled new practices and representations that they also started to develop in the public sphere, for example, working as nurses.
\end{abstract}

DESCRIPTORS: History of nursing. Nursing education. Nursing schools.

\section{LA MUJER INTEGRAL: ENFERMERAS “BLUSAS-VERDES” EN EL SERVICIO DE LA NACIÓN}

RESUMEN: El estudio pretende investigar la actuación designada a la enfermera integralista y la educación que recibió para llevar a cabo con la máxima eficacia su papel en las filas de la Ação Integralista Brasileira, partido político de extrema derecha que surgió en Brasil en la década de 1930. Utiliza como fuente material los periódicos del movimiento, la colección "Enciclopedia Integralista" y los registros sobre la Escuela de Enfermería Integralista que componen la colección penal de la Policía Política, organizado por la Policía Especial de Seguridad Política y Social. Como resultado, el estudio presenta una importante inversión del integralismo en la formación de enfermeras, mujeres que aprovecharon la oportunidad del momento para ampliar sus espacios sociales. Se concluye que, a pesar del integralismo fortalecer los roles sociales descriptos como femeninos, la relación de mujeres con el movimiento fue innovadora, ya que permitió nuevas prácticas y representaciones que ellas comenzaron también a desarrollar en el ámbito público, como ejemplo, la representación como enfermeras.

DESCRIPTORES: Historia de la enfermería. Educación en enfermería. Las escuelas de enfermería. 


\section{CONSIDERAÇÕES INICIAIS}

A década de 1930 representou um marco na trajetória da política social brasileira, uma vez que a "questão social" passou a receber um tratamento diferenciado em relação ao período da Primeira República. Uma variedade de orientações ideológicas, presentes especialmente a partir de 1920 (nacionalismo, tenentismo e outras), denota a presença de marcante inquietação e heterogeneidade sociocultural no período.

Nas cidades do Rio de Janeiro e São Paulo, as transformações do espaço urbano e a expansão econômica trouxeram novas oportunidades para as mulheres na esfera pública, possibilitando assim, uma maior visibilidade feminina em espaços antes de exclusividade masculina. ${ }^{1}$

Nesse contexto de mudanças, as mulheres passaram a se fazer mais presentes na vida pública, não só nas manifestações político-partidárias como também no mercado de trabalho, gerando na sociedade brasileira algumas tensões e conflitos diante das inovações culturais do período. Eram solicitadas por vários setores que até então as excluíam, bem como reivindicavam o direito de acesso ao espaço público, mesmo que enfrentando críticas e reações frente às tradições e ao conservadorismo predominante. ${ }^{2}$

Impulsionada pelos acontecimentos do período, em face de uma Nação que buscava se modernizar, a área da saúde pública ampliou suas atividades na sociedade de modo a promover o controle da população mais pobre, mediante a vigilância e a educação sanitária através de visitas domiciliares. Tais intentos possibilitaram às mulheres, que lutavam por um espaço no mercado de trabalho, a atuação como enfermeiras.

Diante das constantes lutas femininas por melhores condições de trabalho e mais igualdade de direitos na sociedade, a Ação Integralista Brasileira (AIB), partido político de extrema direita do Brasil, na década de 1930, não ficou inerte, incentivando o desenvolvimento da enfermagem no interior do movimento. Provavelmente, as conquistas sociais alcançadas pelas mulheres, naquele momento, como a obtenção de empregos, antes restritos aos homens, e o direito ao voto, fizeram a AIB, assim como o restante da intelectualidade, adaptar seu discurso repressor, de forma que atraísse a mulher. ${ }^{3}$
Também para o campo da enfermagem o integralismo direcionou as mulheres militantes, integrantes de suas fileiras. A AIB compreendia que, no exercício da enfermagem, os atributos considerados intrínsecos à natureza feminina eram valorizados, tornando-se indispensáveis à prestação de um cuidado que era, ao mesmo tempo, técnico e abnegado. Assim, a profissão de enfermeira foi entendida como uma extensão do papel da mulher no recesso do lar, como esposa, mãe e dona de casa, no desempenho de funções ligadas ao cuidado do outro, em relação ao qual havia que se exercitar uma vigilância permanente. ${ }^{4}$

O integralismo conferia à mulher enfermeira o papel de combater as endemias existentes, a fim de fazer do povo brasileiro um povo forte, capaz de tornar o País "a potência das potências". Desse modo, a AIB investiu em propagandas e cursos integralistas de enfermagem, formando diversas turmas que atuariam em seus laboratórios, lactários e ambulatórios, além de "[...] servirem nos trabalhos geraes* ou especializados das clínicas privadas, dos hospitaes e, se necessário, nos serviços sanitários nacionaes" .5:4 Os cursos de enfermagem ofertados pela AIB também são objeto de investigação deste estudo.

Considerando a expressividade da AIB no cenário político da época e compreendendo a crescente participação das mulheres na sociedade do período, com destaque neste estudo para a participação da mulher no integralismo, a pesquisa objetiva investigar a atuação designada à enfermeira integralista e a instrução que recebia para desempenhar com a máxima eficácia o seu papel nos quadros da AIB, para que pudesse tornar fortes e saudáveis os integralistas, aptos a lutar pelas causas do movimento.

Ao realizar um levantamento dos estudos desenvolvidos sobre o integralismo e sobre a história da enfermagem na década de 1930 foi possível observar que poucos autores investiram esforços na compreensão sobre a atuação da mulher, como enfermeira, nos quadros da AIB. Pôde-se constatar que as enfermeiras integralistas são mencionadas em estudos ${ }^{4,6-7}$ que se dedicaram a investigar a participação da mulher no integralismo, mas que esses estudos não se aprofundam na análise da temática em questão, limitando-se a apontar a enfermagem como um campo de ação das militantes.

\footnotetext{
* Optou-se por utilizar a ortografia do período - década de 1930, conferindo mais veracidade às transcrições textuais que configuram as citações diretas. Tal opção de escrita se apresenta ao longo de todo o estudo. 
Desse modo, o estudo justifica-se pela análise do destacado papel desempenhado pelas enfermeiras integralistas nas fileiras da AIB e na sociedade do período, dado que assinala uma trajetória histórica não evidenciada pela área da enfermagem. Justifica-se, também, pelo ineditismo da temática, que aponta para um significativo espaço de atuação destinado à mulher numa sociedade em que a esfera pública se caracterizava como um lugar de circulação predominantemente masculina.

\section{ABORDAGEM TEÓRICO-METODOLÓ- GICA}

Esta pesquisa histórica, de cunho qualitativo, ${ }^{8}$ apresenta como recorte temporal o período de 1932 a 1938, cuja delimitação emerge do próprio objeto de estudo, uma vez que 1932 é o ano de fundação da Ação Integralista Brasileira e, 1938, o ano de extinção da Associação Brasileira de Cultura $(\mathrm{ABC})$, antiga AIB. Vale lembrar que no início do Governo ditatorial de Getúlio Vargas todos os partidos políticos foram suprimidos, juntamente com eles a AIB, o que demandou uma readaptação das suas funções, levando-a a se transformar em sociedade civil com a denominação de Associação Brasileira de Cultura. Como ABC, funcionou até 1938, quando foi extinta, e seus líderes foram enviados para o exílio.

O estudo utiliza como fonte documental jornais integralistas - "A Offensiva", "Monitor Integralista" e "Província de Guanabara" - a coleção "Enciclopédia Integralista" e os prontuários sobre a Escola de Enfermagem Integralista, que compõem o acervo criminal da Polícia Política, organizado pela Delegacia Especial de Segurança Política e Social (DESPS/RJ)** e que se encontra no Arquivo do Estado do Rio de Janeiro.

Do jornal A Offensiva, órgão de divulgação doutrinária da $\mathrm{AIB}$, foram selecionados cinco artigos e algumas notas, dos 748 exemplares publicados, de 17 de maio de 1934 a 19 de março de
1938. As notas publicadas nas seções Movimento Integralista e na Página Médica possibilitaram o acompanhamento dos acontecimentos ocorrentes na Escola de Enfermagem da AIB. Do jornal Monitor Integralista, periódico doutrinário e prescritivo do movimento, publicado da primeira quinzena de 1933 (n. 1) a 7 outubro de 1937 (n. 22), foram utilizados os Estatutos da Secretaria Nacional de Arregimentação Feminina e dos Plinianos*** (SNAFP), presentes no exemplar de número oito, que foi veiculado em 1934. Do jornal Província de Guanabara, o estudo fez uso das notícias referentes ao Curso Prático de Enfermagem, com ênfase à notícia publicada em 19 de abril de 1937, presente na página dois do exemplar quatro, que tratava da organização do referido curso.

À Enciclopédia Integralista, composta por um compêndio de textos elaborados por integrantes da AIB, inclusive por alguns escritos do Chefe Nacional do movimento, Plínio Salgado, recorreu-se para análise e compreensão sobre o Regimento da Secretaria Nacional de Arregimentação Feminina e dos Plinianos, que coordenava, de modo mais abrangente, todas as atividades femininas no integralismo, inclusive as atividades desempenhadas pelas enfermeiras. Finalmente, recorreu-se aos prontuários da Polícia Política, órgão de repressão do governo no período, para análise dos documentos apreendidos e dos relatórios elaborados após a extinção da AIB, por determinação do governo ditatorial de Vargas.

A seleção do material se deu pelo levantamento prévio dos artigos e documentos relacionados à temática em questão. Como ferramenta metodológica foi utilizada a análise dos documentos em separado e, posteriormente, relacionados entre si. Desse entrecruzamento entre as diferentes fontes de pesquisa foram elaboradas unidades de significado que possibilitaram melhor compreender a atuação das enfermeiras nos quadros do integralismo e as ações empreendias pelo movimento para a formação dessas militantes.

** A Delegacia Especial de Segurança Política e Social (DESPS) do Distrito Federal/RJ, criada em 1933, pelo Governo Vargas, atuou na repressão à Ação Integralista Brasileira a partir de 1937, quando foram extintos os partidos políticos em função do golpe de Estado. A partir do Ato do Governo, a DESPS fechou núcleos integralistas e apreendeu todo o material que neles encontrou, tais como cartas, jornais, folhetos propagandísticos, canecas, pratos, bandeiras, mesas, cadeiras, fotos, quadros, macas, balanças, uma ambulância, etc.

*** A AIB utilizou o termo "Plinianos" para designar os jovens de até 15 anos de idade, de ambos os sexos, inscritos nas fileiras integralistas e que compunham o Departamento dos Plinianos. Eles eram assim chamados em homenagem ao Chefe Nacional Plínio Salgado. 


\section{RESULTADOS E DISCUSSÃO}

\section{A Ação Integralista Brasileira e atuação feminina em seus quadros}

Com Núcleos organizados em todo território nacional e contando, em 1937, com mais de um milhão de adeptos, segundo informações divulgadas em o Monitor Integralista, a AIB buscou transmitir a imagem de um movimento preocupado com a população, com os problemas sociais do Brasil. O integralista, além dos deveres para com a Pátria e com o movimento, que iriam até o sacrifício da própria vida, teria o dever de prestar assistência e socorro a todos os brasileiros.

Para levar a cabo seus intentos de conquistar novos adeptos, inclusive por intermédio da caridade e beneficência, o integralismo não poupou esforços e atuava com vigor nos centros beneficentes, ambulatórios e lactários por intermédio das militantes. Compreendendo a nova posição social que a mulher assumia e sua presença mais marcante no espaço público, o integralismo aproveitou para direcionar a "energia feminina" para as atividades de assistência social, educação e saúde, além do trabalho de arregimentação e doutrinamento de jovens e crianças. ${ }^{9}$

As mulheres inscritas na AIB eram chamadas de "blusas-verdes", em alusão ao uso do uniforme constituído por blusa de meia-manga de cor verde. Essa vestimenta deveria ser utilizada pela militante em aparições públicas, desfiles, reuniões, batizados, casamentos e outros eventos integralistas ou não-integralistas, sendo seu uso obrigatório em solenidades do movimento.

A presença oficial feminina na AIB, na qualidade de membros efetivos, foi definida institucionalmente a partir do Regimento da Secretaria Nacional de Arregimentação Feminina e dos Plinianos (SNAFP), aprovado em 10 de agosto de 1936, obedecendo aos princípios hierárquicos da agremiação. ${ }^{10}$

Nota-se que a Secretaria era chefiada por mulheres e a posse dos cargos era comemorada em reuniões solenes e divulgada nos jornais integralistas que enfatizavam a "[...] nobreza de caráter da mulher integralista, sendo ela a mais indicada para organizar e chefiar o trabalho das companheiras blusas-verdes". 10:168 A SNAFP compreendia dois Departamentos: Feminino e dos Plinianos.

De acordo com o regimento da SNAFP, o Departamento Feminino tinha por objetivo " $[\ldots]$ orientar, dirigir, controlar e arregimentar as ati- vidades Femininas no Movimento", 10:170 e o Departamento dos Plinianos "[...] reunir, disciplinar e educar, por intermédio da escola ativa, todos os brasileiros, de ambos os sexos, até 15 anos de idade, de modo a realizar o seu aperfeiçoamento moral, cívico, intelectual e físico" . ${ }^{10: 174}$

O Departamento Nacional Feminino era composto por cinco Divisões: “Expediente, Cultura Physica, Educação, Estudos e Ação Social". Sob responsabilidade da "Divisão de Cultura Physica", ficava a orientação às integralistas no que se refere ao desenvolvimento físico, assim como a manutenção de aulas de ginástica e a prática dos esportes "apropriados ao sexo feminino". ${ }^{10: 170}$

As atividades assistencialistas desenvolvidas pelas mulheres na AIB eram coordenadas pela Divisão de Assistência Social, que tinha por finalidade "[...] prestar assistência e proteção assídua às integralistas e simpatizantes, assim como a todas as classes sociais, agindo especialmente nos meios proletários, dentro do campo de suas atribuições" ${ }^{11: 9}$

A cultura e "o aprimoramento do espírito" da mulher integralista eram buscados por meio das ações da Divisão de Estudos, uma das mais importantes e atuantes da SNAFP. Essa Divisão, compreendida pelos setores de Cursos e Conferências, tinha como objetivo não só "promover e orientar cursos especializados de Sociologia, Filosofia e Pedagogia", 10:172 mas também, "promover sistematicamente" conferências sobre Economia Social, Geografia Humana, Literatura, Arte e Formação Moral e Cívica. ${ }^{10: 173}$

A Divisão de Educação, por sua vez, deveria orientar as atividades femininas nos setores de Alfabetização, Enfermagem, Puericultura, Datilografia, Culinária, Corte e Costura, Boas maneiras e Contabilidade Caseira e Economia Doméstica. ${ }^{10}$

Era constante, no discurso integralista, a ideia de que a "mulher, devido a sua natureza, tinha grande contribuição a dar na tarefa da educação da consciência nacional", ${ }^{12: 53}$ discurso permanentemente vinculado à AIB que se utilizava ordenadamente das senhoras e moças inscritas, encaminhando-as principalmente para os setores educacionais.

Juntamente com a Divisão de Ação Social, a Divisão de Educação foi amplamente utilizada pelo movimento integralista para divulgar sua doutrina. Por meio de suas atividades, realizava propagandas e doutrinava quem aos núcleos integralistas comparecesse. 
Era de competência da Divisão de Ação Social, por meio dos setores Lactários, Bandeirantes e Dispensários, "aplicar no terreno social as atividades das integralistas, contribuindo assim de maneira eficiente e constante para o melhoramento material e moral das condições de vida da família brasileira" ${ }^{10: 173}$

As integralistas operavam no setor da educação sanitária e da medicina preventiva, contribuindo para o aprofundamento do debate entre os médicos e sanitaristas do período. Por intermédio da SNAFP, elas organizavam núcleos de atividades públicas ligadas à medicina preventiva contra doenças sexualmente transmissíveis e outras.

A Divisão de Ação Social, segundo Estatutos expostos no jornal Monitor Integralista da primeira quinzena de dezembro de 1934, compreendia quatro Seções: Escolar, Técnica, Médica e de Bandeirantes da Caridade, sendo a Seção Escolar responsável por "manter o quadro de professoras e distribuí-las pelas escolas que a AIB [fosse] criando; incumbir-se da educação dos plinianos infantis, criando jardins da infância; colaborar no Departamento da Juventude, na parte relativa à Seção Feminina; agir nas escolas públicas, orientando a educação infantil no sentido da doutrina integralista; criar 'Escolas de Férias', nas montanhas e nas praias; levar ao conhecimento do Chefe da Divisão as falhas verificadas". ${ }^{13: 4}$

À Seção Técnica cabia organizar e manter cursos especializados de culinária, corte e costura, boas maneiras, contabilidade caseira, especialidades técnicas diversas; "[...] organizar visitas, excursões e bandeiras, ministrando ao povo conhecimentos técnicos de higiene, de alimentação, de preservação da saúde etc"; e apresentar relatórios quinzenalmente. ${ }^{13: 4}$

À seção Médica competia "organizar cursos especializados de enfermagem; prestar os primeiros socorros médicos, injeções etc; organizar os demais serviços especializados que se [prendiam] a essa Seção" ${ }^{13: 4}$ À Seção de Bandeirantes da Caridade cabia "organizar visitas domiciliares aos pobres da AIB, levando-lhes periodicamente sua assistência; organizar visitas a hospitais, casa de saúde e asilos; visitar fábricas, centros femininos, companhias, estabelecimentos comerciais e repartições públicas, etc, assistindo a mulher que trabalha e indagando de suas necessidades e aspirações". ${ }^{13: 4}$

Os Estatutos apontam que essa Divisão, a Divisão de Ação Social, deveria manter estreita ligação com o Departamento de Assistência Social, respeitar suas determinações e prestar-lhe apoio ou dele se utilizar, quando necessário, cabendo a cada Seção de Assistência Social sua instalação e funcionamento.

Dentre as áreas nas quais as atividades sociais eram realizadas pelo movimento, a maternidade recebia uma atenção especial, visto que representava o lugar da evolução e da preservação da família. A principal tarefa desses núcleos de assistência social, assim como dos ambulatórios que dependiam deles, era orientar as mulheres pobres sobre a higiene e a saúde do corpo e os cuidados com os filhos. Outra preocupação das mulheres integralistas era evitar a disseminação de duas doenças que muito matavam no período: a tuberculose e o câncer.

A AIB conferia destacada importância à maternidade e apontava não se resumir_apenas a uma função física, porque seria, principalmente, uma função moral, não terminando com o nascimento da criança, nem com seu aleitamento, tendo a mãe de continuar, por motivos religiosos e razões científicas, acompanhando os filhos na infância, na puberdade, na juventude e até mesmo em toda a vida. Sob certos aspectos, destacava o integralismo: "o homem é produto da mulher, dado que é geralmente o que a sua mãe quis e, muitas vezes, o que sua esposa quer que ele seja. É dela a responsabilidade de estimular nele virtudes com a finalidade de torná-lo um homem de nobres ideais amanhã". ${ }^{14}$

$\mathrm{Na}$ visão integralista, as funções sociais da mulher deveriam prolongar psicologicamente as físicas, sendo a maternidade a função que a distinguiria do homem, pois, tendo filhos ou não, o essencial era que a ação da mulher se exercesse num sentindo maternal e, mesmo sendo solteira, deveria ela assumir espiritual e sentimentalmente essa função. ${ }^{11}$

Nesse sentido, as integralistas tiveram um significativo papel social na educação e orientação de mulheres pobres gestantes. Elas alertavam a respeito da importância do diagnóstico precoce e dos cuidados com a alimentação para a saúde da mulher e da criança. Também falavam sobre a necessidade da amamentação. $\mathrm{O}$ espaço da rua era sempre caracterizado como inóspito e perigoso para as futuras mães e para as jovens senhoras, por ser um local em que circulavam muitas doenças que ameaçavam não apenas os adultos, mas também as crianças, que poderiam ficar "marcadas para sempre". ${ }^{11: 9}$ 


\section{A Escola Integralista de Enfermeiras e o Curso de Enfermagem}

Para formar "blusas-verdes" aptas a orientar as militantes inscritas em suas fileiras, a AIB criou e inaugurou, no dia 3 de outubro de 1935, a primeira Escola Integralista de Enfermeiras, sendo tal feito comemorado com uma reunião solene que foi divulgada em $A$ Offensiva do dia 5 do mesmo mês. ${ }^{5}$

A reunião, ocorrida no salão da Rua Sachet, da Província da Guanabara, de acordo com o impresso, estava repleta de jovens e mulheres inscritas nas fileiras da AIB. Na cerimônia, foram enaltecidos os esforços empregados pela mulher integralista para a inauguração da Escola, assim como seu espírito de perseverança e realização que "[...] estão acima de quaisquer comentários" .5:4

Dr. Alberto da Cunha, diretor técnico da instituição, usou a palavra para abordar o papel da mulher no movimento, mencionando ser a Escola de Enfermeiras o espaço onde "[...] a mulher poderá desempenhar a mais nobre das missões, dentre todas aquelas que mais condizem com seus sentimentos de afetividade" . 5:4

Presidiram a cerimônia a Chefe do Departamento Provincial Feminino Maria Reis Telles Ferreira, acompanhada da Chefe do Departamento Nacional Feminino Irene de Freitas Henriques e das respectivas chefes de divisão.

Com o início das aulas do curso provisório marcado para 4 de outubro de 1935 e o término previsto para dezembro do mesmo ano, a Escola, sua estrutura e seu programa, que foi elaborado com auxílio de vários médicos, foram apresentados ao grupo ali reunido.

No momento, foi lembrado, pela secretária da Escola, Wilma Villard, que as companheiras que frequentassem o curso provisório de noções de enfermagem e recebessem o certificado de habilitação estariam dispensadas do exame de admissão do curso definitivo, cujo início estava agendado para janeiro de 1936. Esse procedimento foi adotado pelo movimento, segundo A Offensiva, ${ }^{5}$ com intuito de atrair a atenção das militantes para que viessem a se matricular no curso definitivo, garantindo um satisfatório número de inscritas.

A Escola Integralista de Enfermeiras era subordinada a Divisão de Assistência Social do Departamento Provincial Feminino e objetivava educar enfermeiras profissionais a fim de servirem nos trabalhos gerais ou especializados das clínicas privadas, dos hospitais e, se necessário, nos serviços sanitários nacionais. ${ }^{15}$
O seu funcionamento se dava em locais determinados pela Chefia Provincial Feminina que, quando possível, entrava em acordo com as instituições médicas gerais ou especializadas, preferencialmente de integralistas ou simpatizantes, a fim de que cedessem espaços para realização dos exercícios práticos. ${ }^{15}$

A direção da Escola era exercida por uma enfermeira profissional diplomada ou excepcionalmente por quem a Chefia Provincial Feminina determinasse, devendo ter experiência em administração. A nomeação em comissão ao cargo de diretora era feita pela Chefia Provincial Feminina. ${ }^{15}$

No evento de inauguração da Escola, os nomes das "blusas-verdes" escolhidas para ocuparem cargos de direção já começam a figurar, como é o caso de Adele Castro que, após ocupar "interinamente" com "extremada dedicação" o cargo de Chefe do Departamento Feminino, fora nomeada tesoureira da Escola. Nesse contexto, é possível observar militantes que ocuparam cargos administrativos de responsabilidade e de elevada importância dentro dos núcleos, escolas e departamentos da AIB, o que possivelmente contribuiu para atrair um elevado número de adeptas às causas e doutrina do movimento. ${ }^{15: 4}$

Dentre as obrigações exercidas pela diretoria da Escola estavam: “a) esforçar-se pelo progresso e engrandecimento moral e material da Escola; b) cumprir e fazer cumprir este regulamento [o regulamento da Escola de Enfermeiras Integralistas] e as demais ordens provenientes das altas autoridades e encaminhadas pela Chefia Provincial Feminina; c) ordenar a abertura e encerramento das inscripções para matrículas e exames; d) despachar o expediente; e) abrir e encerrar os livros da Secretaria, autorizar despesas e visar as contas apresentadas; f) apresentar boletins mensaes e relatórios semestraes da administração à chefia Provincial Feminina; g) organizar um quadro de auxiliares da Secretaria, fazendo o regulamento interno das funcionárias, submetendo tudo à apreciação da Chefia Provincial Feminina, a fim de serem feitas por esta autoridade as nomeações necessárias". ${ }^{\text {15:1 }}$

Por determinação do Conselho de professores e diretores da Escola, o Curso de Enfermagem se daria através do ensino teórico-prático no período de um ano. Após seis meses de curso das disciplinas, as alunas seriam submetidas às provas escritas e depois de um ano, aos "exames teórico-práticos orais". ${ }^{15: 1}$

A AIB conferia importância primordial ao que denominou de "exercícios e exames teórico- 
-práticos" para treinamento de suas enfermeiras, devendo elas dominar os conteúdos teóricos aliados aos conhecimentos adquiridos na prática. Tais preceitos foram ressaltados no discurso da professora Maria Ribeiro dos Santos Teres, realizado no dia 7 de outubro, primeiro dia de aula na Escola de Enfermagem. Em sua fala, a oradora ressaltou a necessidade de agregar teoria e prática no processo de ensino-aprendizagem, expondo que o curso provisório estaria restrito a aulas teóricas que preparariam as alunas para as aulas práticas a serem ministradas posteriormente no curso definitivo: “[...] devo dizer-vos, que ninguém se tornará enfermeira sem que tenha passado pela experiência dos hospitais. O conhecimento teórico é indispensável, mas indispensável, também é a prática hospitalar. O conhecimento da enfermeira não pode ser unilateral. É indispensável, é imprescindível, que ela procure integrar a cultura científica à experimentação". 16:4

Ainda nesse discurso, foram pontuados os atributos necessários para o trabalho de enfermagem, entre eles a abnegação, a paciência, a renúncia, a ilimitada capacidade de sacrifício. Para Teres, esses atributos as mulheres da AIB possuíam, e ela justificou sua afirmação com essas palavras: "[...] sois integralistas! Abraçastes uma doutrina que conduz à espiritualidade", 16:4 uma doutrina que conduz ao "amor, à ternura" ${ }^{16: 4}$ Logo depois de findado o discurso, ela ministrou a primeira aula do curso provisório que duraria pouco mais de dois meses.

De acordo com o Regimento da Escola, no primeiro ano de funcionamento do Curso de Enfermagem, curso definitivo com duração de doze meses, os programas seriam organizados pela diretoria com auxílio dos professores. Esses programas deveriam ser submetidos à avaliação para aprovação pela Chefia Provincial Feminina e só assim poderiam ser implantados.

A diretoria da Escola e o corpo docente constituiriam a Congregação Escolar de Enfermagem que, oportunamente, organizaria um Regimento Interno para os seus trabalhos, inclusive os trabalhos de organização de programas.

A Escola de Enfermagem funcionava orientada por um sentimento paternalista em que os professores escolhidos eram, de preferência, integralistas dentre os profissionais brasileiros natos ou naturalizados. Esses professores eram nomeados pelo Chefe Provincial da Guanabara, mediante proposta da Chefia Provincial Feminina. Cabia ao professor: a) reger a disciplina para que tivesse sido nomeado, "zelando pelo ensino e agindo com pontualidade e assiduidade"; b) organizar os programas da respectiva disciplina para ser discutido e aprovado pela diretoria escolar e Congregação; c) comparecer aos exames e reuniões convocadas pela diretoria da Escola e propor a aquisição de materiais relativos à sua cadeira, zelando pelo material que lhe fosse confiado; d) indicar, nos impedimentos temporários, um substituto que regeria sua cadeira provisoriamente. ${ }^{15: 2}$

Como exigências para admissão no curso as candidatas deveriam preencher a "folha de admissão" declarando nome, idade, cor, filiação, naturalidade, residência, certidão de nascimento, atestado de vacinação, atestado de que não sofriam de moléstias contagiosas, atestado de boa conduta, documento comprobatório de instrução secundária. Na ausência do documento comprobatório da instrução secundária, a candidata era submetida a um "exame vestibular" sob os critérios da Chefia Provincial Feminina. ${ }^{15: 2}$

Os exames realizados pelas alunas da Escola de Enfermagem eram divididos em duas etapas, sendo a primeira constituída por uma prova escrita com 10 perguntas sobre o assunto da matéria de cada cadeira examinada e a segunda etapa constituída por provas teórico-práticas orais. $\mathrm{Na}$ segunda etapa, os exames de cada disciplina eram prestados perante uma comissão formada por três professores, designados pela diretora da Escola, sob a presidência do professor da disciplina pela qual a aluna estava sendo avaliada. As alunas aprovadas nas cadeiras do curso receberiam os diplomas de Enfermeiras Integralistas. ${ }^{15}$

Do Programa Geral do curso constavam as seguintes disciplinas: " 1 - Da arte de enfermeira; 2 - Dados históricos de enfermagem; 3 - Anatomia; 4 - Physiologia; 5 - Physica e Chimica applicadas; 6 - Noções de Phatologia interna e externa; 7 - Microbiologia (noções); 8 - Parasitologia (noções); 9 - Therapeutica e pharmacologia (noções); 10 - Higiene e saúde pública; 11 - Administração hospitalar; 12 - Administração de um serviço de enfermeiras; 13 - Methodos usuaes na arte de enfermeiras; 14 - Cozinha dietética e nutrição lactários; 15 - Higiene individual; 16 - Serviços de enfermeira na (radiologia, doenças contagiosas, doenças transmissíveis, clínica médica, clínica cirúrgica, doenças da pelle, doenças venereas, tuberculose, doenças nervosas, doenças mentaes, clínica pediátrica, obstetrícia, gynecologia, clínica dentaria, ophtamologia, estômato-oto-rhino-larincologico); 17 - Questões sociais e profissionais da 
enfermagem; 18 - Serviço publico e privado; 19 - A enfermeira e seu campo de acção" . 15:3

Os núcleos integralistas poderiam organizar cursos intensivos de enfermagem com instrução teórica e prática para visitadoras e serviços de ambulatório, enfermarias, enfermagem domiciliar, sendo os programas organizados anualmente pela direção de tais serviços e apresentados aos respectivos chefes dos núcleos para a devida aprovação legal. Os certificados desses cursos davam direito à matrícula, independente de qualquer outro documento, no Curso de Enfermagem da Escola Integralista de Enfermeiras. ${ }^{15}$

Semestralmente, os núcleos deveriam enviar uma relação do número de enfermeiras diplomadas, com os respectivos nomes e residências, para a formação do quadro de enfermeiras integralistas, que ficaria sob a dependência da Secção Médica da Divisão de Assistência Social Feminina.

No jornal integralista Província de Guanabara, publicado no dia 19 de abril de 1937, uma nota intitulada Curso Prático de Enfermagem destaca que haviam se encerrado, no dia 10 de abril, as inscrições do curso a ser realizado naquele ano, com a inscrição de 44 moças. Também faz saber o jornal que havia ocorrido a primeira reunião conjunta em que se fizeram presentes as candidatas e os professores do curso. O encontro serviu ao propósito de definir horário e local de realização das aulas. Segundo a nota, o curso teria início no dia 19 do corrente mês, na Santa Casa da Misericórdia, com uma aula inaugural proferida pelo Dr. Adalberto Severo, professor da cadeira de microbiologia. ${ }^{17}$

Na ocasião, a diretoria do curso aproveitou o espaço do jornal para se "confessar" amplamente satisfeita com o resultado da "etapa preliminar da jornada que emprehendeu" e agradeceu pela "destreza e devotamento" 17:2 com que os médicos integralistas ocorreram para oferecer sua colaboração à causa do movimento.

Ao se referir às inscritas, o jornal destaca que "o grande número de candidatas attesta, evidentemente, que alguma cousa nova está nascendo no Brasil", 17:2 sendo essa "cousa nova", segundo o periódico, uma nova era de altruísmo, de abnegação, de devotamento.

Possivelmente, as militantes desejosas de mais liberdade, percebendo as concessões que a AIB lhes abria e apropriando-se, de modo singular, do que lhes era imposto, aproveitaram para ampliar e firmar seus espaços na sociedade, utilizando o Curso e a Escola de Enfermagem como meios de extensão de suas atividades sociais. Muitas inscritas se viam obrigadas, por motivos financeiros, ou decidiam, por vontade de participar de modo mais direto da vida pública, dedicar parte do tempo a atividades de enfermagem nos núcleos e escolas integralistas.

A adesão das militantes ao Curso de Enfermagem foi ressaltada pelo jornal Província de Guanabara, de 19 de abril de 1937, como uma expressão do devotamento da militante ao movimento e as "ideias novas", demonstrando "que as nossas patrícias inscriptas [...] se encontram impregnadas do sentido da nossa Revolução [...] porque, em meio ao egoísmo, ao immediatismo, ao utilitarismo burguez da ambiência liberal, assumiram uma 'attitude differente' dispostas a grandes renúncias e a ingentes sacrifícios em prol da Nação". 17:2

Em A Offensiva de 1936, uma nota chama a atenção para o "espírito altruísta da blusa-verde", 18:1 qualidade considerada imprescindível à enfermeira cuja a criação de ambulatórios em várias regiões brasileiras atestava o grande interesse em "concorrer com o seu auxílio médico em benefício das populações abandonadas" ${ }^{18: 1}$ Cuidar do outro constituía-se como um dever que cabia à mulher integralista, pois "agindo em benefício da collectividade, nada mais [fazia] que seguir o seu traçado de civismo e de progresso, auxiliando na formação da Nação e na revolução espiritual". . $^{18: 1}$

De fato, o integralismo pretendia realizar uma "revolução espiritual" com a educação, a cultura, a disciplinarização, a higienização e promoção de saúde das massas, colaborando para a criação de um novo tipo de homem apropriado à sociedade que surgia e aos ideais que AIB disseminava.

Os cuidados com o outro que deveriam se iniciar na infância, dado que as crianças eram vistas como o futuro da AIB e da Pátria, refletiam grande parte dos esforços do integralismo na formação de uma raça forte. Nesse sentido, os cuidados com as crianças pobres eram os mais enfatizados pelo movimento e pelas militantes enfermeiras: "queremos cuidar dos pequeninos caboclos de ventre grande cheios de vermes que lhe sugam o sangue, a energia e a vida... Queremos todas as crianças sofredoras, desamparadas ou mal orientadas, todas! Todas! [...]. Vestindo a blusa-verde assumimos um compromisso sério, uma tarefa árdua, seremos nós que faremos os integralistas de amanhã". ${ }^{19: 2}$

Além dos serviços domiciliares, do atendimento aos pobres em ambulatórios e lactários, do acompanhamento as grávidas, o integralismo também buscou realizar, através das atividades femininas, uma campanha em prol de uma vida 
saudável. A seção "Conselhos de Hygiene", presente diariamente no jornal integralista $A$ Offensiva, orientava as mulheres para que viessem a adotar em seus lares, com suas famílias, uma alimentação saudável, práticas esportivas, etc. As orientações direcionadas à mulher deveriam ser compartilhadas, por recomendação do jornal, com as companheiras integralistas e não-integralistas, nos núcleos, nos clubes e onde mais estivesse a militante em contato com outras mulheres.

Os discursos médico-higienistas foram amplamente propagados na primeira metade do século $X X$, voltando-se para a saúde física e mental. Uma faceta desses discursos centrava-se no condicionamento do projeto civilizatório brasileiro à higienização do mundo social. A população brasileira foi alvo, naquele momento, de inúmeros produtos e serviços que buscavam garantir uma vida saudável. ${ }^{20}$

O integralismo, aproveitando o ensejo do momento, também divulgou em seus jornais inúmeros produtos e serviços que, segundo apregoava, confeririam à mulher a possibilidade não só de gerar, mas também de criar filhos fortes e sadios, futuro promissor de um País em via de modernização e de uma Nação Integralista que se buscava instituir. ${ }^{4}$

Apesar da ampliação dos papéis atribuídos pela sociedade à mulher, a AIB compreendia que a emancipação feminina precisava ser tomada com cautela, uma vez que deveriam ser estabelecidos certos limites para as aspirações femininas.

Vários empecilhos foram impostos ao acesso a determinadas profissões, pois ainda assim, esperava-se que as mulheres, antes de se dedicarem ao trabalho remunerado, fossem boas donas de casa, boas mães e esposas. Além disso, as ofertas disponíveis, em geral, estavam próximas daquilo que se considerava uma extensão das atribuições das mulheres e somente profissões como professora, datilógrafa, telefonista, secretária e, destacadamente, enfermeira eram bem vistas em função dos interesses integralistas.

\section{CONSIDERAÇÕES FINAIS}

A pesquisa evidenciou que embora a AIB reforçasse os papéis descritos socialmente como femininos, a relação das "blusas-verdes" com o movimento foi inovadora, no sentido que possibilitou às mulheres novas práticas e representações que elas passaram também a desenvolver na esfera pública.
A mulher integralista, segundo os documentos analisados, aderiu à causa social do integralismo, prestando-se as diversas atividades para as quais foi convocada. A Escola de Enfermeiras recebeu inúmeras inscrições e o Curso de Enfermagem formou um grupo bastante significativo de militantes da AIB.

Conferir abertura às mulheres que estavam ganhando espaço no mercado de trabalho, a despeito da ameaça ao núcleo familiar, do temor à dissolução da família que representava a educação da mulher, ainda que contrariando os escritos dos integralistas mais conservadores, parecia, pelo que tudo indica, ser uma tentativa de atrair não só as donas de casa, mas também as mulheres que queriam ou precisavam trabalhar, lutavam por seus direitos políticos e se identificavam com discursos imbuídos de argumentos antifeministas, anticomunistas e cristãos.

O integralismo compreendia que através das atividades assistencialistas e de cuidados com o outro, desenvolvidas pelas militantes integralistas, poderia estender seu alcance propagandístico, doutrinando suas fileiras e conquistando novos membros. As concessões no tocante aos comportamentos e papéis sociais representavam muito mais uma tentativa de atrair e arregimentar novos adeptos do que um esforço de reformulação idealística e doutrinária.

Para atingir seus intentos, o integralismo buscou ampliar a participação feminina nos lactários, ambulatórios e nos núcleos integralistas, incentivando as "blusas-verdes" a se inscreverem nos cursos de enfermagem que ofertava. Ainda que a atividade como enfermeira e os cursos de enfermagem fossem esteados com o fim nem tanto oculto de divulgação e convencimento ideológico, a atuação de mulheres integralistas como enfermeiras possibilitou a ampliação da circulação feminina em espaços públicos e a sanção dos novos papéis sociais atribuídos à mulher.

Os cursos de enfermagem da AIB constituíram-se como importantes atrativos para as mulheres militantes e não militantes e o movimento soube investir nessa estratégia para conquistar a simpatia feminina e expandir seus quadros. Atrair e arregimentar as mulheres que haviam acabado de conquistar o direito ao voto a fim de inchar seus quadros e agregar novos eleitores levou a AIB a assumir uma nova postura em face da parcela feminina da sociedade.

O esforço realizado nesta pesquisa representa um passo inicial na investigação da temática 
em questão, abordagem que necessita de amplos investimentos em função da riqueza das fontes e da expressividade do integralismo na sociedade dos anos 1930. Por ora, o estudo limitou-se a destacar uma faceta histórica ainda pouco evidenciada e que requer novos olhares: a oferta de cursos de enfermagem pela AIB na década de 1930 e a significativa adesão de mulheres a esses cursos, mulheres que entendendo as oportunidades que lhe eram concedidas, aproveitaram para ampliar seus papéis sociais como enfermeiras "blusas-verdes".

\section{REFERÊNCIAS}

1. Goellner SV. Bela, feminina e maternal: imagens da mulher na Revista Educação Physica. Ijuí (RS): Ed. Ijuí; 2003.

2. Besse SK. Modernizando a desigualdade: reestruturação da ideologia de gênero no Brasil, 1914-1940. São Paulo (SP): Ed. da Universidade de São Paulo; 1999.

3. Bulhões TS. Evidências esmagadoras de seus atos: fotografias e imprensa na construção da imagem pública da Ação Integralista Brasileira (1932 - 1937) [dissertação]. Rio de Janeiro: Universidade Federal Fluminense, Instituto de Ciências Humanas e Filosofia; 2007.

4. Simões RD. A educação do corpo no jornal A Offensiva (1932-1938) [tese]. São Paulo: Universidade de São Paulo, Programa de Pós-Graduação em História da Educação e Historiografia; 2009.

5. Inauguração da Escola de Enfermagem. A Offensiva, 1935 Out 5; 73(2):4.

6. Cavalari RMF. Integralismo: ideologia e organização de um partido de massa no Brasil (1932-1937). São Paulo: EDUSC; 1999.

7. Mancilha VMN. Nas páginas da imprensa feminina: uma análise da revista Brasil Feminino e da participação no movimento do Sigma. In: Gonçalves LP, Simões RD, organizadores. Entre tipos e recortes: histórias da imprensa integralista. Guaíba (RS): Sob Medida; 2011. p. 47-82.
8. Padilha MICS, Borenstein MS. O método de pesquisa histórica na enfermagem. Texto Contexto Enferm. 2005 Out-Dec; 14(4):575-84.

9. Simões RD. Integralismo e ação católica: sistematizando as propostas políticas e educacionais de Plínio Salgado, Jackson de Figueiredo e Alceu Amoroso Lima no período de 1921 a 1945 [dissertação]. São Paulo: Pontifícia Universidade Católica de São Paulo. Programa de Pós-Graduação em Educação, História, Política e Sociedade; 2006.

10. Henriques IF. Regimento da Secretaria Nacional de Arregimentação Feminina e dos Plinianos. Regulamento, art. $1^{\circ}$. Enciclopédia do Integralismo. Rio de Janeiro: Clássica Brasileira, 1959; IX: p. 168-74.

11. Secretaria Nacional de Organização Política Departamento feminino: Cap. IV das divisões. Monitor Integralista, 1934 Dez; 8(2):9.

12. Penna B. A mulher e a família, o lar e a escola. Enciclopédia do integralismo. Rio de Janeiro (RJ): Clássica Brasileira, 1959; IX: p. 41-59.

13. Salgado P. Resoluções da Chefia Nacional. Monitor Integralista, 1934 Dez; 8(2):4.

14. Salgado P. Discurso às estrelas. Obras Completas. São Paulo (SP): Editora das Américas, 1955; XX:p. 37.

15. Escola de Enfermeiras. Divisão de Assistência Social. Departamento Provincial Feminino. In: Arquivo Público do Estado do Rio de Janeiro - Fundo Polícia Política - Setor Integralismo; s/d: p. 1-3.

16. Teres MRS. Escola de enfermeiras da Ação Integralista Brasileira. A Offensiva, 1935 Out 12, 74(2):4.

17. Curso prático de enfermagem. Província de Guanabara, 1937 Abri 19; 4(1):2.

18. Página da Blusa-verde. A Offensiva, 1936 Jun 2; 195(3):1.

19. "A mulher e a educação". A Offensiva, 1934 Set 6; 17(1):2.

20. Gondra J. Modificar com bravura e prevenir com cautela. Racionalidade médica e higienização da infância. In: Freitas MC, Kuhlmann M, organizadores. Os intelectuais na história da infância. São Paulo: Cortez; 2002. p. 289-318. 